\title{
Editorial. The roots and routes of Environmental and Sustainability Education policy research
}

\author{
Katrien Van Poeck (Ghent University) \\ Jonas A. Lysgaard (Aarhus University)
}

\section{Introduction}

Although until recently it has been labelled an 'emerging field' of scholarship, environmental and sustainability education (ESE) research has experienced a significant growth in its scholarly literature over the past few decades (Wright and Pullen 2007; Scott 2009). Not only has there been an increase in the number of research articles on ESE, but also growth in the scholarly journals in which they are published and in the variety of academic authors writing about ESE. Arguably, these are all signs of a healthy and vibrant research field. But in order to fully exploit its potential, and to determine and discuss new directions and priorities for future research, a strong sense of the field's history and directions remains of utmost importance.

As early career researchers with an explicit wish to contribute to this field for the next 30-40 years, we were keen to accept an invitation to compose a first 'virtual special issue' (VSI) for Environmental Education Research focused on ESE policy research. Unlike a regular special issue, the aim of such a collection is not that of gathering new articles with a common focus, but rather exploring the body of ESE policy research literature published in the journal and bringing this together as a well-considered selection on the Journal's website.

Identifying key arguments, perspectives and approaches in the existing ESE policy research literature as well as connections with related fields of scholarship, through this stock-taking project we have sought to detect novel insights that might inspire future ESE policy and policy research. We were encouraged, however, to not stop there. With this VSI, our ambition has been to view such a collection of articles as a warm invitation for further research and debate to all interested researchers and fields, however close or distant neighbours they might be. While a good research field needs its own sense of history, it also needs friends and allies that will fill the future with intriguing and demanding collaborations, clashes, ruptures and perhaps even nuptials.

In 2006, Alan Reid and William Scott pre-figured some of these considerations in their comments on a collection of papers for a special issue, 'Researching education and the environment: retrospect and prospect', to mark the first 10 years of the journal. They argued that it is important to consider not just the 'roots' of the field but also the 'routes' into, across and out of this field (Reid and Scott 2006: 574). With this VSI we strive to rise to, and revisit, their challenge. 
First, we aim to contribute to the collective development of a critical historical consciousness of the patterns and tensions in the field and how these are working. Next, we want the VSI to reveal and discuss some of the 'routes' affecting ESE policy research by addressing its relations with other academic fields, as well as the connections between research, policymaking and practice. And finally, throughout our discussions and reflections, to focus particular attention on the role and position of researchers within the tensions that characterise the roots and routes of ESE policy research.

\section{The roots of ESE policy research}

We started our explorations of the ESE policy research literature for this VSI by surfacing and discussing our assumptions about the field, and then scrutinising them in light of a reading of all the back issues of Environmental Education Research, in order to identify research articles addressing key aspects of ESE policy. A screening of article titles and abstracts allowed us to quickly identify key arguments, perspectives, patterns and tensions characterising this 'transect' of the history of ESE policy research and, subsequently, to develop a shortlist of papers to be considered for this VSI collection.

Each of the articles we ended up including address at least one of the key topics we elaborate below. By bringing them together in a VSI, highlighting shared as well as diverging arguments and perspectives and connecting discussions in early work to ideas and arguments developed in recent articles, we trust the VSI will offer readers a genealogy of the field.

Obviously, it can't pretend to be a neutral or objective representation of the field's history, but rather reflects the way in which ESE policy research articles in the journal have spoken to two emerging researchers against the backdrop of lively debates in contemporary ESE scholarship, as well as the theoretical inquiries and discussions in which we are engaged.

With this collection then, we hope to foster renewed interest in formerly published work as well as in longer-lasting and evolving discussions in the field of ESE policy research. This, we hope, might inspire other researchers to supplement or question our reflections presented below, while suggestions for further research we have already developed in accompanying introductions to the VSI. After all, developing a sense of history of a scholarly field cannot be left to individual or a few researchers. Rather, drawing lessons from earlier research should be a collective endeavour and responsibility to which this VSI modestly aims to contribute.

Through our explorations, wider consultations, various iterations, and 'editorial feedback', we have settled on the following key topics as foci for our selection for the VSI:

- the sensitive and contentious character of ESE and, thus, ESE policy;

- the purpose and focus of ESE and how this is or should be reflected in policymaking as well as in the naming of the field;

- the focus on providing solutions;

- the role and position of ESE (policy) researchers. 


\section{A contentious and politically sensitive field of scholarship}

In revisiting all the past volumes of the journal, one of the first things we noticed was that even within its first few issues, scholars regularly claim that ESE policy research is anything but a neutral field of scholarship and that it inevitably involves controversy and political sensitivity.

For example, in their article about the development of a National Guideline for environmental education in New Zealand, Law and Baker (1997) highlight the dilemmas and tensions involved in this process as well as the sensitive and contentious nature of environmental education within a wider political environment. Their study emphasises the importance and difficulties of involving and acknowledging multiple viewpoints (e.g., Maori perspectives) in consultation and policy-making processes, and they go on to describe a key tension between passion for a particular policy and its political acceptability, if not expediency.

To date, this has remained a topic of keen interest in ESE policy research, as illustrated by McKenzie et al.'s (2015) article in one of the journal's more recent issues. McKenzie and colleagues highlight the politics involved in the production and implementation of ESE policy and its productive and/or restraining effects on how sustainability is being conceived and mobilised in and through educational policy. ESE policy research should not be reduced to a quasi-neutral tool for enabling rational or technical decision-making, they argue. Rather, concerned with the twinning of sustainability with priorities of economic neo-liberalisation in education, researchers should address the fact that every policy serves some particular interest more than others. So rather than offering yet more findings, advice or simple solutions as to 'best' policy, the research community - including its champions and communicators - should also address the complex underlying factors that influence which policies may be developed, emulated, passed on, or passed over.

Returning to Law and Baker, they connect the political sensitivity of such ESE policy research to bureaucratic procedures and formal processes of government policies, but do so without explicitly relating the controversies involved to the specific character of the subject matter, that is, the complex, uncertain and contested nature of environmental and sustainability issues. Interesting insights and perspectives on the latter have later been developed by other scholars however, operating in another time and context. The societal and policy context surrounding ESE research in, for instance, Sweden and Denmark (Læssøe and Öhman 2010) differs considerably from the environmental education policy in New Zealand of the 1990s, and that too might also be considered a test-case for the neo-liberalist approaches to ESE recently criticised in a Special Issue of this Journal (Hursh et al. 2015).

As democracy is a deeply rooted value in these Northern European societies, the strong commitment to researching democratically-oriented forms of ESE and for investigating how norms and values are constituted and selected in ESE practices is perhaps not surprising. Sund and Öhman (2014), for example, theorise the philosophical problems involved in embracing universal values and ethical ideals in ESE. Viewing universal values and ideals as essential aspects of political life, they argue for repoliticising ESE by unmasking its political 
dimension, dealing seriously with plurality and conflicts, seeing beyond the relativistobjectivist divide and using passion as a moving force.

Whereas Sund and Öhman question a universal ethical foundation for dealing with environmental and sustainability issues, Ashley (2000) problematizes an absolute conception of scientific 'truth' in this respect. In his article about the uneasy relationship between science and environmental education, he discusses the powerful yet provisional nature of scientific truth. He points to the limits of science as a 'model of rightness' that can tell us what to do and thus, offer us 'an escape' from the responsibility for those of our actions that have detrimental environmental consequences. Hence, he argues for curriculum policies that acknowledge a 'science of uncertainty' and a 'science with limits'. Preparation for adult life in a risk society, he stresses, requires general scientific literacy, scientific action competence, and an education in the philosophy, values clarification and citizenship skills needed to responsibly participate in a society of reflexive modernity. Returning to McKenzie et al. (2015), a key question here is not just the mobility of policy, but the epistemic and ontological aspects to notions of those policies and pedagogies that make or inhibit their mobility. For example, in a globalised discourse of ESD, can an umbrella organisation for Regional Centres of Expertise avoid necessary questions of how situated knowledges and practices can and can't be disseminated, transferred or modified?

The on-going struggle of pinning down the ESE field - or even of taming it - and finally understanding what it is about is certainly a glorious struggle. It will go on, and so should it, as the field moves under its own momentum and that brought about by others. A formless shapeshifter it is not, but from the very early discussions to the contemporary debates about the contentious and political nature of the field, ESE has endured as a wonderful battlefield of different political, ethical and moral interests and perspectives. Surely, one of the greater, yet frustrating, traits of the field?

\section{What's in a name? The purpose and focus of ESE and how this is or should be reflected in policymaking}

Another regularly re-occurring subject of discussion is how the field of research on education in relation to environmental and sustainability issues should be named. Underlying this semantic debate is a discursive struggle between 'competing paradigms' (Aikens et al. 2016), and hence diverging perspectives on the role and purpose of ESE. Two vital topics of disagreement that emerge within this discussion are: environmental education (EE) versus education for the environment (EfE) - a discussion about the purpose of education; and environmental education versus education for sustainable development (ESD) - a discussion centred on the field's subject matter and focus.

In 2002, for example, Stables and Scott argued that the still emerging link between sustainable development and education should be approached cautiously and with a strong sense of the contested nature of the term 'sustainable development'. This is linked with a sharp critique of tendencies towards holistic understandings of concepts such as the 
environment, nature and sustainability within the field of ESE. The two emphasise that our field has been, and can be, severely harmed if we do not approach policy documents and policy-making with a strong pluralistic perspective and a continued focus on 'reflexive critiques of the human-nature relationship'. This does not 'guarantee the saving of the planet from ecological destruction', they admit, but then, 'nothing does’.

Stevenson (2006) looks back on some of the earlier discussions of ESD and what the concept offers the field, in the way of positive outlooks and inclusion of social and economic perspectives. But he also argues that the concept never escapes the fuzziness and ambiguity that is both a blessing and a hindrance for its impact on the policy-practice relationship in ESE. By quoting Stables and Scott (2002), Stevenson, among other things, warns us against the continued danger of a 'gap between policy sloganizing and policy implementation [that] is very great', and against using sustainable development as a 'salvation narrative'. This, he discerns, is a road towards an un-reflexive discourse brimming with unquestioned 'experts', centralised global institutions, and other top-down approaches to educational reform (cf. Huckle and Wals 2015). Yet, educators do not need to adopt a reified vision of 'what ESD should be'. The road ahead, he argued in 2006, should remain that where policy is informed by practitioners and practice in diverse cultural contexts, and engaged in a continuous and reflexive reconceptualization of the discourse of the field.

At this point, we can turn to Ferreira (2009) for further instruction. She presents a metaanalysis and critique of these debates on how we should name and understand our field and how this should be reflected in dealings with policy and practice. She shows how education for the environment or for sustainability has become an orthodoxy, and how different positions of researchers affect what is possible to think and do in ESE. Yet, she is not satisfied with orthodoxies in any guise, and in her barely contained critique of some of the main characters in the debate surrounding the naming of the ESE field and its various constituents and constituencies, she presents a refreshing argument for always questioning 'that which is' both within and outside of a field, and being especially aware of the constant lure of adapting to an orthodoxy. This analysis still rings true, and remains central, especially when dealing with policy perspectives internal and external to the field.

Thus after a decade of meta-reflections and critical perspectives on what constitutes the field of EE/EfE/ESD, Kopnina (2012) kicks the doors in with a heavy critique of the whole field, arguing that we are lost in squabbles over names, policy perspectives and undue pluralism. With a brave return to an explicitly ecocentric position, Kopnina takes a firm stand regarding the purpose of ESE: as environmental problems are severe, education should help their resolution. She argues that the field should put less emphasis on internal discussions about names (EE/ESD) and subnames (sustainable development education, learning for sustainability, education for sustainability, etc.), and instead insists on a radical turn away from neo-liberally and anthropocentrically-biased education.

It is most likely that discussions of what the research field should be called, how it should be bounded, and policed, for that matter, will continue, spurred on by both internal development and the ebbs and flows of policy agendas nationally and internationally. Taking into account 
the diverging arguments of both Ferreira and Kopnina, it does however, seem more important than ever not to accept orthodoxies nor even heterodoxies, and at the same time have the courage to argue that this field must address the important questions of our time, whether or not we agree on what those are.

\section{ESE as a problem solver? Solution-oriented research, policy and practice}

Closely linked with debates around the name of the research field are discussions on how far we can go in instrumentalising both education and educational research and use it directly as a means to finding solutions to the complex and often dizzying challenges that we face. Policymakers and practitioners' demands to do so are well represented down the years of the journal. Clearly there is a great focus on delivering hard evidence, but also practically applicable approaches in order to more or less directly help policymakers and practitioners in creating solutions. Aikens et al.’s (2016) extensive policy research literature review shows how 'sustainability imperatives' such as environmental and socio-cultural degradation have been identified by many ESE policy researchers as important 'policy drivers', that is, as factors that have largely contributed to the development of ESE policy.

A decade ago, Blewitt (2005) commented directly on how a national policy-driven ESD initiative finds itself at the crossroads of a managerial focus on predetermined outcomes and a more heuristic emphasis on how to question the underlying logics of the structures that surround learning today. Dogmatic insistence on pre-specified learning outcomes in terms of observable behaviour change or 'competences', he argued, will usually result in mere indoctrination and impedes the emergence of valuable, transformative learning that needs 'critical and reflective space and time'. This tension pops up again and again in different issues of the journal, and remains a conundrum within the field. How to deal with challenges through a system that represents and mimics these challenges to an extreme extent?

Rudsberg and Öhman (2010) put their trust in pluralist approaches as effective tools against technical proclivities in education tending towards behaviour modification. Through their study they show how it is actually possible to nurture pluralistic meaning making processes. While this might be a sign of a long overdue move away from rather simplistic hopes that implementation of an educational strategy will result in predetermined outcomes, they do themselves warn that pluralism is also a norm. A norm that scorns indoctrination, but still a norm that must be discussed, critiqued and not develop into one of the orthodoxies that Ferreira warns us against. Ferreira herself actually contributes to this discussion by explicitly questioning the open-endedness that is often associated with pluralistic education, wondering how education can be 'anything other than the achievement of some particular end'. All education is purposive and seeks to govern our conduct, she argues, but in so being, there is a huge difference in forming and shaping particular types of persons, e.g., critical thinkers willing and able to shape the future, versus people that are trained for 'correct' behaviour and steered, however gently, towards a particular vision. 
This same tension is interestingly addressed by Mogensen and Schnack (2010) who critically reflect on how the notion of 'action competence' has increasingly been challenged over time by 'new', managerial interests in competences and quality criteria. They argue for resisting individualising and managerial tendencies and emphasise that action competence should remain an 'educational ideal' strongly connected with a concern for democracy, critical reflection, and enlightened and qualified action. One might wonder, however, whether the term 'competences' has not been co-opted too, and included in 'new', managerial orthodoxies too firmly by now, to prevent other understandings of this notion. In this respect, it was invigorating for us to read Stables' (1998) paper about environmental literacy in an early volume of the Journal against the backdrop of this contemporary discussion that concerns us strongly. The distinction he makes between 'functional', 'cultural' and 'critical environmental literacy' creates a space for discussions about the role and purpose of education - a space that is often closed-down in debates focusing on 'competences'.

Furthermore, his analysis of the UK national curriculum guidelines strikingly reveals how it is precisely the objective of fostering critical environmental literacy that threatens to be pushed into the background within policymaking processes.

The insistence on research as a machine that produces evidence-based solutions to complex issues, is not something that will disappear, but something that clearly needs a thorough going over from time to time in order for the field - and we as individual researchers - to be able to defend ourselves, the field and research institutions from too simplistic policy-driven demands for magic bullets if not ammunition, that will rid humanity/nations/societies of pressing problems.

\section{The routes of ESE policy research}

\section{At the crossroads of research, policymaking and practice: the role and position of ESE policy researchers}

Through the above-elaborated focus on offering solutions, ESE policymakers, practitioners and researchers seem to be caught up in a similar tension. Educators and policymakers are increasingly urged to deploy ESE in the pursuit of solving environmental and sustainability problems, and researchers experience a growing pressure to come up with evidence-based solutions and usable instructions for the former to do so, in the most efficient and effective ways. As shown above, several scholars argue for moving ESE policy and practice beyond the prevailing focus on pre-specified outcomes and competences in the pursuit of solving unsustainability. What does this mean, then, for ESE policy research? Aligning ourselves with the critique of ESE as a problem-solver, we believe that our research field must create time and space for more reflexive retrospection rather than for monitoring and evaluating predefined indicators.

Addressing research gaps that emerged from their literature review on ESE policy, Aikens et al. (2016) make a case for increased attention for developments in critical policy research. These include a rejection of positivist frameworks that assume policy (research) to be a neutral process of problem identification and solution. Instead of trying to objectively 
determine 'what works,' critical ESE policy researchers should approach policy-making as a complex process in which multiple actors intervene and influence what counts as policy problems, what solutions are available, and how the latter are 'championed, borne, resisted or subverted in practice'. Acknowledging the tensions this may bring about, they argue that critical ESE policy research must include engagement with policy development and solutions and with generative political action.

Læssøe et al. (2013), too, thoughtfully address these issues in relation to the role and position of ESE policy researchers. Showing an appreciation of researchers' reservations towards cooperating with policy institutions and getting involved in the construction of often narrow policy agendas, they call on ESE researchers to be neither exclusively critically detached, nor naively involved. They make out a case for what Biesta (2009) calls a 'documentary role' of policy research, with interactive researchers that act as 'critical friends' and who document what is actually going on in different contexts and on different levels. Stables' (1998) analysis of the SCAA guidelines and Blewitt's (2005) study of the 'Learning to last' initiative are examples of such documentary research. Recently, Van Poeck et al. (2014) analysed and documented how the UN Decade of ESD has been interpreted and transformed into national policymaking and how the latter influenced ESD practice in Flanders, Belgium. They each argue how the national policymaking process is inextricably intertwined with broader developments in environmental and educational policy, while in the case of Flanders, that give shape to a post-ecologist and post-political policy regime.

Although the latter affects what is possible and acceptable within Flemish ESD policy, Van Poeck and her colleagues conclude that it does not completely determine policy and practice. Just like the case described by Blewitt, the documenting of a policy process reveals emerging discrepancies by showing that what happens at particular instances during this process sometimes opens up a space for resistance against the bounds of dominant policy regimes.

In their article about different conceptual logics for globalisation in relation to ESD policy, Bengtsson and Östman (2015) also articulate a possible political role for ESE policy researchers. Drawing on an empirical analysis of Vietnamese and Thai ESD policy-making, they show how deterministic and universalising research approaches risk eliminating any 'theoretical space for politics'. Instead of focusing on the questions of what ESD ultimately is or should be, they argue, a contingent approach to ESE policy research can draw attention to the much more interesting question of what ESD can become though particular practices in particular spaces (cf. McKenzie et al.’s (2015) arguments for a 'policy mobility’ perspective). Doing so, they emphasise, can open up a space for interference, contestation and counterhegemonic articulations, and foster spaces, even ‘windows of opportunity’ (Hardt and Negri 2000), for influencing policy-makers.

As such, ESE policy research aimed at documenting contingent practices might indeed, as Læssøe et al. (2013) argue, have the potential to incite more democratic and less top-down approaches to policy-making. Yet, this kind of research, we think, also highlights particular ethical and deontological questions that are important to collectively reflect upon as a field. Making spaces for resistance visible, after all, simultaneously renders them vulnerable to be 
tamed or co-opted by hegemonic discourses and regimes. As Hardt and Negri (2000) argue, all concepts potentially lose their critical and emancipating power over time as they get coopted and included into the dominant discourse. Taking this into account thus seems to be a responsibility one cannot escape when engaged in documentary research. It should, therefore, not be aimed at closing discussions but rather at opening up, again and again, an interactive space for critical reflection and dialogue between policymakers, researchers and practitioners.

\section{At the crossroads of academic fields: routes into and out of ESE policy research}

While arguing for considering both the roots and routes of the ESE research field, Reid and Scott (2006) also raised the question of whether this field is largely characterised by relations with other fields that function primarily as 'outside in' in terms of orientation and flows of concepts, interests, frameworks and findings, rather than 'inside out'. Reflecting on the articles we considered for this collection, we would say that, indeed, ESE policy research benefits from contributions of different academic fields but all the same it is obvious that our field also has something to offer to other, related fields.

As to the routes 'outside-in', several ESE policy analyses (e.g., Mogensen and Schnack 2010; Rudsberg and Öhman 2010; Van Poeck et al. 2014) clearly draw on theories and insights of educational research and philosophy of education to foster critical reflection on instrumental tendencies in ESE (policy). Also the field of science studies offers valuable insights that are addressed in the articles of, for instance, Stables (1998) and Ashley (2000). Acknowledging too that science cannot offer a monological 'truth' that allows escape from the responsibility to have to make choices, highlights the importance of moving beyond instrumental approaches in ESE practice, policy and research. Furthermore, Stables (1998) and Stables and Scott (2002) show the potential of connecting ESE research with language and literary theory. As we have already argued, the notion of 'literacy' might allow for a more nuanced conceptualisation of the (desired) outcomes of education than a focus on 'competences'. While as Sund and Öhman (2014) demonstrate, the fields of political science and democracy theory also affords interesting ways to deal with the inherent political character of sustainability issues.

Regarding the routes 'inside-out', we believe that by bringing all the aforementioned (and other) insights and perspectives together in a focus on both education and sustainability, ESE policy research clearly has some potential to challenge and inspire other related fields. For instance, the specificity of ESE and particularly the deep concerns about the far-reaching implications of sustainability challenges highlights the importance of 'engaged research' and, in so being, can put relevant ethical and deontological issues on the agenda of (educational) policy research (e.g., Stevenson 2006; Læssøe et al. 2013). Relatedly, the concerns about the consequences of sustainability problems and the undeniable materiality of the latter can challenge certain ideas and perspectives in philosophy of education, (social) constructivism and critical theory by revealing the need to move beyond an exclusive focus on discourse and language and to seriously take the material context of sustainability debates into account. Connecting this again with the 'outside in'-route from science studies to ESE research, we 
also believe that the growing interest in the '(post-)Anthropocene', the 'more-than-human' or 'more-than-social' also will spur interest in the emerging perspectives on how we engage with aspects of objects and subjects that exceeds the boundaries of language. Arguably many a scholar within this field has grown up with theories rooted in the linguistic turn and their associated important focus on power in language, deconstruction of the same, and the possibility of understanding the world through analysis of discourses. Recently new trends have emerged, and discussions about material, topographical or mobility 'turns' are surfacing across very different disciplines and fields. Among the theories that claim to be part of new 'turns' we find 'Speculative realism' (see, for example, Lysgaard and Fjeldsted 2015) that insist on a refreshing focus on objects and the Real that exist outside of language and how this continues to influence the social beyond the discourse.

Another perspective is Mckenzie et al.’s (2015) argument for the importance, within the social sciences, of focusing on 'the immense scale of movement of object, people, and ideas across the globe'. This is in order to 'explain the complex relationship between mobilities, moorings (...), spatial scales, and practices of place making, in order to describe how social worlds, like sustainability policy-making, are in part 'made in and through movement'. These, and other related perspectives (e.g. variants on Actor Network Theory, the new materialisms, etc.), claim to offer new tools that go beyond the strictly discursive and might be able to offer relevant and inspiring ideas, concepts, frameworks and findings to ESE policy research as well as the broader field of educational research. It is tempting to think that the field of ESE, because of the special nature of its areas of research, has the possibility, to be at the tip of the 'theory-developing spear' within educational research. And thus, some of these new exciting turns might find their foothold first in ESE, become translated into educational settings and then passed on to neighbouring fields.

Furthermore, the work done in ESE policy research - drawing on insights from educational and political theory - to criticise instrumental tendencies by conceptualising the political nature of sustainability issues (e.g., Rudsberg and Öhman 2010; Sund and Öhman 2014, Van Poeck et al. 2014) shows a certain overlap and shared concerns with particular perspectives in sustainability science and transition studies that also question instrumental, managerial and mechanistic approaches to sustainability transitions (e.g., Paredis 2013; Devolder and Block 2015). As such, these research fields can be considered complementary and bear potential for mutual synergies.

Operating in a field with fuzzy borders offers great scope for taking in the best of neighbouring fields (however far they might understand themselves to be from us), but also offers great possibility for cross-fertilisation from all of 'us' to all of 'them' (if one believes the purpose of such demarcations). As this collections of illustrative papers shows, the research presented over the years in Environmental Education Research represents a dense and thoughtful body of scholarship that not only stimulates a dynamic and fast-moving field, but also is more than grown enough to influence fields next to us (and perhaps even 'above' and 'under' us). Working with the specific links between education, environment, sustainability and policy has produced insights that remain too good not to revisit, and too good not to share. As such the articles in this VSI do not form a canon of what every good 
ESE researcher should at least know about ESE and policy, but offers everyone a potential vantage point to further push the field from the outside in, to the inside out.

Advancing a research field, we believe, requires more than improving the current scientific state-of-the-art by merely building further on (and, thus, reinforcing) existing theories and findings or by applying the latter to overlooked areas. As Alvesson and Sandberg (2014) argue, generating really interesting novel ideas and potentially influential path-breaking thinking demands that the basic assumptions underlying existing literature are examined, unpacked and challenged. Therefore, new research 'needs to attract attention from other researchers and practitioners, to lead to enthusiasm, to generate "aha" and "wow" moments, to trigger responses such as "I have not thought about this before" or "perhaps I should rethink this theme”, and possibly to act as an effective tool for animating dialogue and reflexivity among practitioners' (p. 24).

Similar considerations both guided the making of this VSI and constitute our hope as to what its publication might enable. Looking back at the laborious yet educative work of exploring all the volumes of the journal in view of the selection of articles, the papers that attracted our attention were not those that presented incremental, all too cautious, irrelevant and/or somewhat predictable or self-evident findings, but those that introduced distinctive voices in the field, that revealed and questioned taken for granted assumptions, and that stimulated transdisciplinarity and perspective-shifting.

Ferreira's (2009) remarkable article about 'orthodoxies' in our field, for instance, or Bengtsson and Östman’s (2015) paper that interestingly points out how the logics of correspondence and determination that are omnipresent in ESE research influence (or constrain) researchers' observations and conclusions and how the exploration of alternative logics, can open-up new entry points for discussion of ESE policy. Alvesson and Sandberg (2014) emphasise that creating interesting and influential research contributions requires precisely such an open-ended, critical inquiry into prevailing assumptions instead of incrementally identifying and filling knowledge gaps in the available literature.

We want to add that, in our view, it also demands collective inquiry and reflection. With this VSI collection and editorial, we modestly aim to contribute to this endeavour by calling for renewed attention to various articles that, in themselves, reveal and challenge orthodoxies in ESE (policy) research, but also by exploring and unpacking some of the internal debates characterising the roots of our field, shed light on interesting routes into/across/out of neighbouring disciplines, policy and practice, and thus bear the potential to bring about 'path(up)setting' (Alvesson and Sandberg 2014, p. 35) transdisciplinary dialogue.

\section{Some concluding thoughts on 'researchers' and 'experts'}

Many of the abovementioned researchers criticised an absolutist understandings of 'truth' as a foundation for addressing sustainability issues in education. We believe that the same criticism - and, thus, the impossibility to deduce from reality ('out there') a pure and monolithical truth that can be translated in undisputable, evidence-based guidelines on how to 
act - also goes for ESE (policy) research. Nevertheless, with this critique of a decidedly (and hence inadequate for these times) Modern approach to research, neither do we want to fall into a postmodern trap that renders some of the abovementioned concerns about the farreaching consequences of sustainability problems simply relativistic, and thus irrelevant within a myriad of different, equally valued opinions and points of view.

What can we learn from the roots and routes of the field to move beyond a dichotomist distinction between modern and postmodern standpoints, and to further develop much-needed 'other-than-modern' (Garrison et al. 2015) approaches to ESE policy research? Taking into account the issues, insights and concerns raised above, an important prerequisite for this seems to be to preserve a space for ESE policy researchers to make 'documentaries' instead of taming and containing their work by the increasing pressure to offer 'evidence'. In line with this, we want to make out a case for letting ESE researchers be researchers instead of forcing them to take up the role of an expert since, as Bruno Latour (2010: 166 - our translation) argues, an expert-position reinforces the problematic Modern demarcation between science and politics:

Basically, the expert (no matter how sympathetic and modest he might be) always reinforces the impossible Demarcation, attempting as he does to conceal from the public the kitchen of science in the making and to protect scientists from the interests and passions of the public. And the worst is that the cover of expertise is just sufficiently solid to allow politicians to hide behind expert's advices so that they do not have to decide by themselves and for themselves.

A journal such as Environmental Education Research can and does contribute to this challenge by creating time and space to report and reflect on the un-pure process of doing research ('the making of' - e.g., Blewitt 2005), to explore the 'roots' of the field as well as the 'routes' into, across and out of this field - crossing boundaries between academic fields and between research, policy and practice. Some of the initial questions that occupied us in preparing this VSI, were 'What has been investigated so far in ESE policy research?', 'What is lacking?' and 'Which approaches are overrepresented?'. Taking into account the above, we can now rephrase these questions. Is the field of ESE policy research characterised by a sound share of 'interesting', path-breaking research, or are incremental, irrelevant contributions over-represented? And are ESE policy researchers - by the context in which they operate governed to act as researchers or as experts?

Reflecting on this in the light of our exploration of the volumes of this journal, we had to conclude that for us - two early career researchers who have written and reviewed for Environmental Education Research but are besides this not involved in the editorial process asking these questions seems more interesting than answering them. We must remember that a Journal 'is not the field' and these are questions that should always be at the forefront of discussions within any field, including the journals that service it. We can gauge the health and vibrancy of our field by how well we all engage with such questions and remain critical of our own work, its impact, and how it adds to the field and its further progress. Therefore, 
we want to end this editorial by staging our questions as an invitation for a collective inquiry and (self-)reflection in ESE (policy) research.

We believe that the questions offer plenty of food for thought for authors, reviewers as well as the editorial board and office. Researchers and authors can reflect on their willingness to challenge their own taken-for-granted set of beliefs and to abandon (or interrupt) their preferred positions and frameworks in favour of exploring new perspectives and alternative assumptions. And what does this mean in terms of researcher identity, professional norms and career options? Reviewers can consider how to balance concerns for encouraging novel and interdisciplinary research contributions on the one hand, and demonstrated familiarity with and attentiveness to ESE research's heritage on the other. Or how to weigh methodological rigour - an important but never sufficient criterion for interesting findings - and less measurable or 'objectified' qualities such as imagination or the potential to unsettle orthodoxies?

The editorial board and office, with their broad view of the 'kitchen' of ESE research literature in the making, have a vital role in creating space for critically examining the roots of the field, for encouraging the exploration of new routes and for enabling dialogue - publicly, on the pages of the journal, or behind the scenes through refereeing communications between a variety of positions, perspectives and academic fields.

We should all ask ourselves what we find in the 'kitchen' of any field and its journals. What tools of the trade are most used? Are there too many or too few chefs around? Any favourite spices that create the flavour this kitchen is renowned (or infamous) for? What dishes are served mostly? And does the audience like what they are served?

We are grateful for the chance to put this VSI together and hope that it can contribute to a better understanding of the inner workings of this particular slice of the field that Environmental Education Research represents, including its past, present and towards a bright(er) future.

\section{Acknowledgement}

The authors owe many thanks to Alan Reid for the inspiring discussions during the making of this VSI, as well as the valuable feedback on an earlier version of this editorial. 


\section{References}

Aikens, K., McKenzie, M. and Vaughter, P. (2016) Environmental and sustainability education policy research: A review of geographic and thematic trends over time, Environmental Education Research, in press.

Alvesson, M. and Sandberg, J. (2014) Problematization meets mystery creation: generating new ideas and findings through assumption challenging research. In E. Jeanes and T. Huzzard (eds.), Critical Management Research: Reflections from the Field (pp. 23-41) London, UK: Sage.

Ashley, M. (2000) Science: An unreliable friend to environmental education?, Environmental Education Research, 6:3, 269-280.

Bengtsson, S. and Östman, L. (2015) Globalisation and education for sustainable development: exploring the global in motion, Environmental Education Research, online first. DOI: $10.1080 / 13504622.2014 .989960$

Biesta, G. (2009) Educational Research, Democracy and TLRP. Methodological Development, Future Challenges. London: TLRP.

Blewitt, J. (2005) Education for sustainable development, governmentality and Learning to Last, Environmental Education Research, 11:2, 173-185.

Devolder, S. and Block, T. (2015) Transition Thinking Incorporated: Towards a New Discussion Framework on Sustainable Urban Projects. Sustainability, 7:3, 3269-3289.

Ferreira, J. (2009) Unsettling orthodoxies: education for the environment/for sustainability, Environmental Education Research, 15:5, 607-620.

Garrison, J., Östman, L. and Håkansson, M. (2015) The creative use of companion values in environmental education and education for sustainable development: exploring the educative moment, Environmental Education Research, 21:2, 183-204.

Hardt, M. and Negri, A. (2000) Empire. Cambridge: Harvard University Press.

Huckle, J. and Wals, A.E.J (2015) The UN Decade of Education for Sustainable

Development: business as usual in the end, Environmental Education Research, 21:3, 491505.

Hursh, D. Henderson, J. and Greenwood, D. (2015) Editorial - Special Issue: Environmental Education in a Neoliberal Climate, Environmental Education Research, 21:3, 299-318.

Kopnina, H. (2012) Education for sustainable development (ESD): the turn away from 'environment' in environmental education?, Environmental Education Research, 18:5, 699717.

Læssøe, J., Feinstein, N. and Blum, N. (2013) Environmental education policy research challenges and ways research might cope with them, Environmental Education Research, $19: 2,231-242$. 
Læssøe, J. and Öhman, J. (2010) Learning as democratic action and communication: Framing Danish and Swedish environmental and sustainability education. Environmental Education Research 16:1, 1-7.

Latour, B. (2010) Cogitamus: Six lettres sur les humanités scientifiques. Paris: La Découverte.

Law, B. and Baker, R. (1997) A Case Study of Dilemmas and Tensions: the writing and consultation process involved in developing a national guideline document for environmental education, Environmental Education Research, 3:2, 225-232.

Lysgaard, J.A. and Fjeldsted, K.L (2015) Education between discourse and matter. In: P. Kemp (ed.) Nature in Education. LIT Verlag Dr. Wilhelm Hopf.

McKenzie, M., Bieler, A. and McNeil, R. (2015) Education policy mobility: reimagining sustainability in neoliberal times, Environmental Education Research, 21:3, 319-337.

Mogensen, F. and Schnack, K. (2010) The action competence approach and the 'new' discourses of education for sustainable development, competence and quality criteria, Environmental Education Research, 16:1, 59-74.

Paredis, E. (2013) A winding road. Transition management, policy change and the search for sustainable development, PhD dissertation, Ghent University, Ghent.

Reid, A. and Scott, W. (2006) Researching education and the environment: retrospect and prospect, Environmental Education Research, 12:3-4, 571-587.

Rudsberg, K. and Öhman, J. (2010) Pluralism in practice - experiences from Swedish evaluation, school development and research, Environmental Education Research, 16:1, 95111.

Scott, W. (2009) Environmental education research: 30 years on from Tbilisi. Environmental Education Research, 15:2, 155-164.

Stables, A. (1998) Environmental Literacy: functional, cultural, critical. The case of the SCAA guidelines, Environmental Education Research, 4:2, 155-164.

Stables, A. and Scott, W. (2002) The Quest for Holism in Education for Sustainable Development, Environmental Education Research, 8:1, 53-60.

Stevenson, R.B. (2006) Tensions and transitions in policy discourse: recontextualizing a decontextualized EE/ESD debate, Environmental Education Research, 12:3-4, 277-290.

Sund, J. and Öhman, J. (2014) On the need to repoliticise environmental and sustainability education: rethinking the postpolitical consensus, Environmental Education Research, 20:5, 639-659.

Van Poeck, K., Vandenabeele, J. and Bruyninckx, H. (2014) Taking stock of the UN Decade of education for sustainable development: the policy-making process in Flanders, Environmental Education Research, 20:5, 695-717. 
Wright, T. and Pullen, S. (2007) Examining the Literature: A Bibliometric Study of ESD Journal Articles in the Education Resources Information Centre Database. Journal of Education for Sustainable Development, 1:3, 77-90. 